\title{
Stability of internal response and external load during 4-a-side football game in an indoor environment
}

\author{
Karel Hůlka*, Radim Weisser, Jan Bělka, and Pavel Háp \\ Faculty of Physical Culture, Palacký University, Olomouc, Czech Republic
}

Copyright: (C) 2015 K. Hůlka et al. This is an open access article licensed under the Creative Commons Attribution License (http://creativecommons.org/licenses/by/4.0/).

Background: Small-sided games (SSG) are spontaneous forms of specific training where exercise intensity can be manipulated mainly by modifying external factors. When using the SSG, there is a risk that the variability of intensity between players and on repetition of SSG may lead to some players training at inappropriate exercise intensities. Objective: The purpose of this study is to determine intra-individual repeatability and inter-individual variability in exercise intensity in small-sided 4on4 football games. Methods: Twenty five highly trained junior football players (age $17.68 \pm 1.52$ years; BMI $23.8 \pm 1.92 \mathrm{~kg} \cdot \mathrm{m}^{-2}$ ) participated in the study. Distance covered (software package Video Manual Motion Tracker 1.0) and heart rate (HR, expressed as a percentage of peak heart rate) were measured. All participants completed three measurements of 4-a-side games for three consecutive weeks. Results: The high intraclass correlation coefficient value (Heart rate [HR]: ICC $=.88,95 \%$ CI [.65, .94]; Distance covered [DC]: ICC $=.76$, 95\% CI $[.66, .96])$ implies a very high level of intra-individual repeatability. The Pearson's correlation coefficient value (HR: $r=.93$; DC: $r=.85$ ) indicates a high correlation between the results of any measurement. Bland and Altman's $95 \%$ limits of agreement were \pm 10.32 beats $\cdot \mathrm{min}^{-1}$ and $\pm 65.46 \mathrm{~m}$ of distance covered. Conclusions: The results of this study demonstrated that measured SSG elicit consistent heart rate responses and external load of the players.

Keywords: time-motion analysis, heart rate, reliability

\section{Introduction}

Football is a very popular team sport with nearly 200 million players (Dupont, Blondel, Lensel, \& Berthoin, 2002). Football contains positive motivational and social factors that may facilitate compliance and persistence with the sport and contribute to the maintenance of a physically active lifestyle (Krustrup, Dvorak, Junge, \& Bangsbo, 2010).

Small-sided games (SSG) are spontaneous forms of specific training where exercise intensity can be manipulated mainly by modifying external factors. Thus, researchers have examined factors that may affect the intensity of SSG such as dimensions of the pitch, number of players, coach encouragement, continuous and intermittent modality, and goalkeepers' participation (da Silva et al., 2011; Hill-Haas, Dawson, Impellizzeri, \& Coutts, 2011). Little and Williams (2006), and Reilly (2005) indicated that high specificity of loading,

\footnotetext{
* Address for correspondence: Karel Hůlka, Department of Sports, Faculty of Physical Culture, Palacký University, tř. Míru 115, 77111 Olomouc, Czech Republic. E-mail: karel.hulka@upol.cz
}

decision making under the pressure of opponents, and keeping players motivated were the most important advantages of using small-sided games in the football training. These drills lead to more specific physiological adaptations and better transfer of improved technical and tactical skills to the game (Hoff, Wisloff, Engen, Kemi, \& Helgerud, 2002; Krustrup et al., 2010; Little \& Williams, 2006). According to Krustrup et al. (2010) using small-sided games two or three times a week, operates significant cardiovascular and muscular adaptations, including muscle growth and elevated muscular strength independent on the level of training, lack of experience with football, gender and age.

For the loading description the heart rate monitoring, rate of perceived exertion, and distance covered was used in the studies of small-sided games (Aslan, 2013; Casamichana \& Castellano, 2010; Castellano, Casamichana, \& Dellal, 2013; Dellal, Hill-Haas, LagoPenas, \& Chamari, 2011; Hill-Haas, Rowsell, Dawson, \& Coutts, 2009; Rampinini et al., 2007). For distance covered measurement GPS techniques were used (Casamichana \& Castellano, 2010; Castellano, Casamichana, \& Dellal, 2013) or by video analysis (Jones $\&$ Drust, 2007). According to Drust, Atkinson, and 
Reilly (2007) the usefulness of the available data to the end user is dependent on the application of correct measurement methods, which is why the reliability of measurement by the new technique has to be verified. According to Little and Williams (2006) when using the SSG, there is a risk that the variability of intensity between players and on repetition of SSG may lead to some players training at inappropriate exercise intensities. The purpose of this study is to determine intraindividual reproducibility, inter-individual variability in exercise loading measurement (expressed by average heart rate and distance covered) in chosen 4-a-side football and futsal game at indoor environment.

\section{Methods}

\section{Participants}

Twenty five highly trained junior football players $\left(\right.$ age $=17.68 \pm 1.52$ years; $\mathrm{BMI}=21.69 \pm 1.19 \mathrm{~kg} \cdot \mathrm{m}^{-2}$; peak heart rate $=197.88 \pm 5.48$ beats $\cdot \mathrm{min}^{-1}$ ) participated in the study. They trained five times per week (four technical-tactical practices and one conditioning practice). All procedures were conducted during the pre-competitive part of season (December 2013 and January 2014). The aims and objectives of the present study have been clarified to all participants and all of them gave a voluntary written informed consent. Participation was voluntary and players could withdraw from the study at any time.

\section{Procedures}

All participants completed peak heart rate $\left(\mathrm{HR}_{\text {peak }}\right)$ measurement by Léger beep. The measurement was performed during training following one day off (Tuesday) and one week before the first measured training with 4-a-side game. To find out $\mathrm{HR}_{\text {peak }}$ heart rate (HR) measures during Léger beep test were performed using the TEAM Polar ${ }^{2}$ Pro system (Polar Electro, Kempele, Finland).

\section{4-a-side football and futsal game}

The observed participants used blue T-shirts with large orange numbers (corresponding with official football rules) to permit clear identification. The 4-a-side football and futsal game (SSG) was played on a $40 \times 20 \mathrm{~m}$ court 4 on 4 players with goalkeepers. The SSG was played three times per four minutes with four minutes recovery interval. Given to time of measurement the indoor environment in the gym with wooden floor was chosen as an alternative to outdoor environment in case of bad weather.

The footage of SSG was recorded with two Canon HF10 video cameras (each with a resolution of
$1280 \times 720$ pixels). Each camera was used to record a separate half of the court. One camera was placed perpendicular to the side line $(620 \mathrm{~cm}$ above the surface, $840 \mathrm{~cm}$ from the side line) in the middle of the first recorded half of the basketball court. The second camera was placed in an analogous manner to record the second half of the court. To obtain distance covered (an indicator of external load) footages of SSG were analysed by a standardised procedure (Hůlka, Cuberek, \& Svoboda, 2014) using a software package Video Manual Motion Tracker 1.0 (Palacký University Olomouc, Czech Republic). The heart rate was monitored during all measurements by TEAM Polar ${ }^{2}$ Pro system (Polar Electro, Kempele, Finland) and results were expressed as a percentage of $\mathrm{HR}_{\text {peak }}$ of each participant.

\section{Statistical analyses}

Software SPSS (Version 17; SPSS, Chicago, IL) was used to process the data. To detect a repeated measurement differences, one-way ANOVA was used on three repeated assessments and was expressed by a parallel form of the intraclass correlation coefficient (ICC). The average intraclass correlation coefficient was calculated using the formula: $\mathrm{ICC}=(\mathrm{MSS}-\mathrm{MSE}) \cdot \mathrm{M}^{-1}$, where MSS is the mean square of the subjects, MSE is the mean square of the error, and MS is the mean square), which is an indicator of intra-individual reliability (reproducibility). The typical error of measurement (TEM) was calculated according to Hopkins (2000) and expressed as a percentage of the mean (\%TEM) to indicate intra-individual reproducibility. Bland and Altman's 95\% limits of agreement for repeated measurements were used to express the absolute reliability in the original measurement units (Atkinson \& Nevill, 1998). To determine inter-individual variability coefficient of variation $(\mathrm{CV})$ was used (Atkinson \& Nevill, 1998). The statistical significances of all parts of the analysis were determined at an alpha level of $p<.05$.

\section{Results}

The average heart rate was $161.80 \pm 10.60$ beats $\cdot \mathrm{min}^{-1}$ (from 136.29 to 189.48 beats $\cdot \mathrm{min}^{-1}$ ) during the first measurement, $157.50 \pm 11.30$ beats $\cdot \mathrm{min}^{-1}$ (from 137.71 to 183.81 beats $\cdot \mathrm{min}^{-1}$ ) during the second measurement and $158.20 \pm 8.60$ beats $\cdot \mathrm{min}^{-1}$ (from 132.29 to 181.25 beats $\cdot \mathrm{min}^{-1}$ ) during the third measurement. These values correspond to $81.79 \pm 3.29 \%, 79.69 \pm 2.73 \%$, and $80.20 \pm 3.01 \%$ of $\mathrm{HR}_{\text {peak }}$. The average distance covered was $558.27 \pm 43.61 \mathrm{~m}$ (from 512.29 to $602.13 \mathrm{~m}$ ) during the first measurement, $543.83 \pm 36.83 \mathrm{~m}$ (from 503.46 to $598.91 \mathrm{~m}$ ) during the second measurement 
and $539.43 \pm 42.86 \mathrm{~m}$ (from 492.29 to $591.73 \mathrm{~m}$ ) during the third measurement.

According to the one-way ANOVA findings (Table 1), within a five percent significance, there were no statistically significant differences (HR: $F=0.31$, $p=.73$; DC: $F=0.21, p=.69$ ) between the results obtained from the first, second and third measurements, thus we excluded possible differences of repeated measurements for both variables. The high intraclass correlation coefficient value (HR: $I C C=.88,95 \% C I[.65$, $.94]$; DC: $I C C=0.76,95 \% C I[.66, .96])$ implies high level of relative intra-individual repeatability. The TEM values showed absolute values of repeatability for HR: 3.73 beats $\cdot \mathrm{min}^{-1}$ and distance covered $31.11 \mathrm{~m}$. These values represent only $5.58 \%$ (\%TEM) of the average distance covered and $2.35 \%$ (\%TEM) of average heart rate. Bland and Altman's 95\% limits of agreement were \pm 10.32 beats $\cdot \mathrm{min}^{-1}$ and $\pm 65.46 \mathrm{~m}$ of distance covered error interval of intra-individual reproducibility. The $\mathrm{CV}$ analysis showed high level of inter-individual stability of heart rate measurement (2.13\%) and distance covered $(5.16 \%)$ during monitored SSG.

\section{Discussion}

Reliability is a theoretical concept that is used to describe the quality of a measurement instrument. Researchers require evidence of reliability for precise control of exercise intensity and will allow the application of chosen training parameters to produce intended physiological and performance adaptations (Little \& Williams, 2006). The purpose of this work is to determine intra-individual repeatability and interindividual variability in exercise loading expressed by average heart rate by TEAM Polar ${ }^{2}$ Pro system and distance covered by Video Manual Motion Tracker 1.0 in a chosen 4-a-side football and futsal game in an indoor environment.

The results showed that average heart rate and distance covered by players during SSG was not weighted by systematic bias. The absence of significant differences among three repeated measurements showed that measured 4-a-side game posed adequately low tactical pretentions to players. We think that during tactically too loaded SSG the learning effect could manifest by decreasing of physiological demands (Gabbett, Carius, \& Mulvey, 2008). With increasing experience with SSG can players solve game situations more economically and it could decrease the work load.

The results of intra-individual reproducibility, expressed by ICC and \%TEM, showed high reliability of both measured variables, which is very important quality of monitored SSG for practical application. These findings are very similar to results of other studies. Little and Williams (2006) measured heart rate of players in SSG with different number of players and found out high reproducibility with typical error of measurement from 2.1 to $3.8 \%$. Hill-Haas, Coutts, Rowsell, and Dawson (2008) showed typical error of heart rate measurement expressed in percentage from $1.9 \%$ to $4.4 \%$, and from $2.2 \%$ to $6.4 \%$ for distance covered.

The $C V$ analysis showed high level of inter-individual stability of heart rate measurement (2.13\%) and distance covered (5.16\%) during monitored SSG. Similar low inter-individual variability of internal response expressed by $C V$ showed Little and Williams (2006) moved from 1.4 to 2.8\%. Nevill and Atkinson (1997) the $C V$ values should be ranged 1.4 to $2.5 \%$, our results

Table 1

Overview of reliability analysis indicators

\begin{tabular}{lcc}
\hline & \multicolumn{2}{c}{ Level of indicator } \\
\cline { 2 - 3 } Type of analysis / indicator & HR & DC \\
\hline Detection of systematic bias & $F=0.314, p=.73$ & $F=0.21, p=.69$ \\
One-way ANOVA & .88 & .76 \\
Intra-individual reproducibility & \pm 10.32 beats $\cdot \mathrm{min}^{-1}$ & $\pm 65.46 \mathrm{~m}$ \\
Intra-class correlation coefficient & 3.73 beats $\cdot \mathrm{min}^{-1}$ & $31.11 \mathrm{~m}$ \\
$95 \%$ limits of agreement & $2.35 \%$ & $5.58 \%$ \\
TEM & & \\
$\% T E M$ & $2.13 \%$ & $5.16 \%$ \\
Inter-individual variability & & \\
Coefficient of variation &
\end{tabular}

Note. $\mathrm{HR}=$ heart rate monitoring, $\mathrm{DC}=$ time-motion analysis, $T E M=$ typical error of measurement, \%TEM = typical error of measurement expressed in percentage. 
fulfil this criterion. We did not find any study for $C V$ of distance covered.

In sports games it is very important to ensure receiving the same training load for all players to prevent undertraining or overtraining (Little \& Williams, 2006). To check the intra-individual reproducibility and inter-individual variability is crucial for practical application of SSG because using SSG with good interindividual variability supports unified training load for all players and will allow for the provision of a progressive training load over time (Klusemann, Pyne, Foster, \& Drinkwater, 2012). Moreover it facilitates the planning of the training process and more training time could be spent as team training including SSG with simultaneous specific endurance, technical, and tactical development. According to Gabbett, Jenkins, and Abernethy (2010) SSG with good reproducibility and variability allow greater transfer of physiological adaptations, because the players simultaneously develop technical and tactical skills under high physical load, and hence skill executions per player, and higher motivation of athletes (Klusemann et al., 2012).

Similarly, Hill-Haas et al. (2008) larger reproducibility and variability of external load than internal response lead to recommendations for coaches to prefer internal response to evaluate the work load during SSG.

We consider the indoor measurement without comparison with the results of the same outdoor measurement (by different techniques), in natural football environment as a limit of our study, which should be solved by next measurement. Simultaneously thanks to indoor measurement the measured internal response could be lower than outdoor on the grass because of the different surface (Andersson, Ekblom, \& Krustrup, 2008; Hughes et al., 2013), temperature, and humidity.

\section{Conclusion}

The results of this study demonstrated that measured SSG elicit consistent heart rate responses and external load of the players and it enables repetitively optimized group training. We think this is very important attribute of every small-sided game which could be measured before its practical application. The size of the work load showed that SSG are a suitable indoor alternative to develop specific football aerobic endurance. We think that a comparison with outdoor games still needs to be measured.

\section{References}

Andersson, H., Ekblom, B., \& Krustrup, P. (2008). Elite football on artificial turf versus natural grass: Movement patterns, technical standards, and player impressions. Journal of Sports Sciences, 26, 113-122.

Aslan, A. (2013). Cardiovascular responses, perceived exertion and technical actions during small-sided recreational soccer: Effects of pitch size and number of players. Journal of Human Kinetics, 38, 95-105.

Atkinson, G., \& Nevill, A. M. (1998). Statistical methods for assessing measurement error (reliability) in variables relevant to sports medicine. Sports Medicine, 26, 217-238.

Casamichana, D., \& Castellano, J. (2010). Time-motion, heart rate, perceptual and motor behaviour demands in small-sides soccer games: Effects of pitch size. Journal of Sports Sciences, 28, 1615-1623.

Castellano, J., Casamichana, D., \& Dellal, A. (2013). Influence of game format and number of players on heart rate responses and physical demands in small-sided soccer games. Journal of Strength and Conditioning Research, 27, 1295-1303.

da Silva, C. D., Impellizzeri, F. M., Natali, A. J., de Lima, J. R. P., Bara, M. G., Silami-Garcia, E., \& Marins, J. C. B. (2011). Exercise intensity and technical demands of smallsided games in young Brazilian soccer players: Effect of number of players, maturation, and reliability. Journal of Strength and Conditioning Research, 25, 2746-2751.

Dellal, A., Hill-Haas, S., Lago-Penas, C., \& Chamari, K. (2011). Small-sided games in soccer: Amateur vs. professional players' physiological responses, physical, and technical activities. Journal of Strength and Conditioning Research, 25, 2371-2381.

Drust, B., Atkinson, G., \& Reilly, T. (2007). Future perspectives in the evaluation of the physiological demands of soccer. Sports Medicine, 37, 783-805.

Dupont, G., Blondel, N., Lensel, G., \& Berthoin, S. (2002). Critical velocity and time spent at a high level of $\mathrm{VO}_{2}$ for short intermittent runs at supramaximal velocities. Canadian Journal of Applied Physiology, 27, 103-115.

Gabbett, T. J., Carius, J., \& Mulvey, M. (2008). Does improved decision-making ability reduce the physiological demands of game-based activities in field sport athletes? Journal of Strength and Conditioning Research, 22, 2027-2035.

Gabbett, T. J., Jenkins, D. G., \& Abernethy, B. (2010). Physiological and skill demands of 'on-side' and 'off-side' games. Journal of Strength and Conditioning Research, 24, 2979-2983.

Hill-Haas, S., Coutts, A., Rowsell, G., \& Dawson, B. (2008). Variability of acute physiological responses and performance profiles of youth soccer players in small-sided games. Journal of Science and Medicine in Sport, 11, 487-490.

Hill-Haas, S. V., Dawson, B., Impellizzeri, F. M., \& Coutts, A. J. (2011). Physiology of small-sided games training in football: A systematic review. Sports Medicine, 41, 199-220.

Hill-Haas, S. V., Rowsell, G. J., Dawson, B. T., \& Coutts, A. J. (2009). Acute physiological responses and time-motion characteristics of two small-sided training regimes in 
youth soccer players. Journal of Strength and Conditioning Research, 23, 111-115.

Hoff, J., Wisloff, U., Engen, L. C., Kemi, O. J., \& Helgerud, J. (2002). Soccer specific aerobic endurance training. British Journal of Sports Medicine, 36, 218-221.

Hopkins, W. G. (2000). Measures of reliability in sports medicine and science. Sports Medicine, 30, 1-15.

Hughes, M. G., Birdsey, L., Meyers, R., Newcombe, D., Oliver, J. L., Smith, P. M., \& Kerwin, D. G. (2013). Effects of playing surface on physiological responses and performance variables in a controlled football simulation. Journal of Sports Sciences, 31, 878-886.

Hůlka, K., Cuberek, R., \& Svoboda, Z. (2014). Time-motion analysis of basketball players: A reliability assessment of Video Manual Motion Tracker 1.0 software. Journal of Sports Sciences, 32, 53-59.

Jones, S., \& Drust, B. (2007). Physiological and technical demands of $4 \mathrm{v} 4$ and $8 \times 8$ games in elite youth soccer players. Kinesiology, 39, 150-156.

Klusemann, M. J., Pyne, D. B., Foster, C., \& Drinkwater, E. J. (2012). Optimising technical skills and physical loading in small-sided basketball games. Journal of Sports Sciences, 30, 1463-1471.

Krustrup, P., Dvorak, J., Junge, A., \& Bangsbo, J. (2010). Executive summary: The health and fitness benefits of regular participation in small-sided football games. Scandinavian Journal of Medicine and Science of Sports, 20 (Suppl. 1), 132-135.

Little, T., \& Williams, A. G. (2006). Suitability of soccer training drills for endurance training. Journal of Strength and Conditioning Research, 20, 316-319.

Nevill, A. M., \& Atkinson, G. (1997). Assessing agreement between measurements recorded on a ratio scale in sports medicine and sports science. British Journal of Sports Medicine, 31, 314-318.

Rampinini, E., Impellizzeri, F. M., Castagna, C., Abt, G., Chamari, K., Sassi, A., \& Marcora, S. M. (2007). Factors influencing physiological responses to small-sided soccer games. Journal of Sports Sciences, 25, 659-666.

Reilly, T. (2005). An ergonomics model of the soccer training process. Journal of Sports Sciences, 23, 561-572. 